\title{
COVID-19 Outbreak in Africa: Lessons and Insights from the West African Ebola Virus Disease Epidemics
}

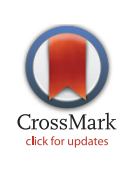

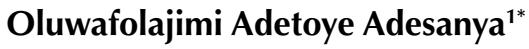 \\ ${ }^{1}$ Institute for Advanced Medical Research \& Training (IAMRAT), College of Medicine, University of Ibadan, Ibadan, \\ Nigeria
}

Corresponding Author: Oluwafolajimi Adesanya, MD, Institute for Advanced Medical Research \& Training (IAMRAT), College of Medicine, University of Ibadan, Ibadan, Nigeria. Tel: +234-9060173391, Email: folajimiadesanya@gmail.com

Received May 10, 2020; Accepted July 5, 2020; Online Published July 25, 2020

\begin{abstract}
Over the years, the African continent has had to battle several outbreaks of infectious diseases in different countries. Some of the most deadly were the Ebola virus disease (EVD) outbreaks that occurred in West Africa between 2014 and 2016 affecting Guinea, Liberia, and Sierra Leone and, more recently, from 2018 to 2020 in the Democratic Republic of Congo (DRC). In the era of the COVID-19 pandemic, it is important that as a continent, we draw lessons and insights from our past experiences to guide outbreak response strategies being deployed to curb the latest onslaught. The Ebola outbreaks have shown that disease outbreaks should not be seen only as medical emergencies, but as full blown humanitarian crises, because oftentimes, their socio-economic impacts are more devastating than the more obvious cost to life. In this mini-review, we explore the possible humanitarian costs of the COVID-19 pandemic on the African continent by looking through the lens of our past experiences with the EVD outbreaks, highlighting how the current pandemic could significantly affect the African economy, food security, and vulnerable demographics, like children and the sexual and reproductive health and rights of women and girls. We then proffer recommendations that could be instrumental in preventing a double tragedy involving the devastating health consequences of the virus itself and the deadly fallout from its multi-sectoral knock-on effects in African countries.

Keywords: COVID-19, SARS-CoV-2, Ebola Virus Disease, Coronavirus
\end{abstract}

Citation: Adesanya OA. COVID-19 outbreak in Africa: lessons and insights from the West African Ebola virus disease epidemics. Int J Travel Med Glob Health. 2020;8(3):96-99. doi:10.34172/ijtmgh.2020.17.

\section{Introduction}

Since the first case of COVID-19 in Africa was confirmed in Egypt on February 14, 2020, ${ }^{1}$ the deadly pandemic has embarked on a vicious spread across the continent, infecting 414,011 people and causing 10,260 fatalities in all 54 African countries as of July 4, 2020 according to data from the Africa Centre for Disease Control and Prevention (Africa CDC). ${ }^{2}$ Barely a week after the first African case was confirmed, the virus had arrived in sub-Saharan Africa, with Nigeria recording its own first case on February 28, 2020, ${ }^{3}$ causing several governments to intensify measures to curb the voracious spread of the pandemic. Over the past several weeks, temperature checks at points of entry and in public gatherings have been deployed for increased surveillance; flights have been halted and air, land and sea borders have been closed; public gatherings have been either prohibited entirely or held under tight restrictions.

While such actions may represent uncharted territory for some countries, for many African nations who went through the Ebola outbreaks of 2014 to 2016 (Guinea, Liberia, and Sierra Leone) and 2018 to 2020 (Democratic Republic of Congo), these are strangely familiar scenes. The response to the Ebola crises has taught African countries invaluable lessons about the possible effects of another outbreak of such magnitude on lives and livelihoods. An effective response to COVID-19 will require that these lessons are built upon.

Here, we briefly review some lessons and insights that can be drawn from the West Africa Ebola virus disease (EVD) outbreaks so as to draw policy recommendations which would be instrumental to the success of the COVID-19 response strategies being deployed around the world, especially in nations with fragile healthcare systems and infrastructures.

\section{On Food Security}

A major consideration for governments during any infectious disease outbreak is the effect of the ensuing social and economic disruptions on the agricultural sector vis-a-vis food supply and availability. During and following the Ebola

Copyright $\odot 2020$ The Author(s). This is an open-access article distributed under the terms of the Creative Commons Attribution License (http:// creativecommons.org/licenses/by/4.0), which permits unrestricted use, distribution, and reproduction in any medium, provided the original work is properly cited. 
outbreaks in the West African sub-region, disease epicenters reported higher food insecurity than the surrounding areas due to the closure of most markets and others operating at reduced capacity. Similar effects have been noted in multiple countries currently battling the COVID-19 pandemic. In one World Bank report, sharp spikes in food prices were noted, for example, an $86-\mathrm{kg}$ bag of yams being sold for close to $200 \%$ its initial price in parts of the Democratic Republic of Congo (DRC). ${ }^{4}$ The United Nations' Food and Agriculture Organization (FAO) has warned that the COVID-19 pandemic could trigger a global food crisis, unless measures are taken to protect the agricultural produce supply chain, ${ }^{5}$ Moreover, a World Food Program (WFP) report, analyzing the potential impact of the pandemic on the world's poorest people, established that an increase in food insecurity in the world's most deprived regions, as a result of some of the disruptive measures being implemented to curb the pandemic, could be more devastating than the health consequences of the pandemic itself. ${ }^{6}$ However, in the midst of the problem lies the solution. It is clear that the restrictions and Limitations being put in place in the face of the rapidly progressing pandemic are having a negative effect on food supply logistics. Therefore, by keeping the markets operational and making exceptions for the free movement of food during this crisis, governments will help protect the food supply chain and ensure that food prices remain stable and the risk of a food crisis is sufficiently mitigated. ${ }^{4}$

\section{On Livelihoods and the Economy}

Self-isolation and social distancing were some of the most difficult concepts to accept for those who lived through the Ebola outbreaks in West Africa, as it had severe financial effects which weighed heavily on their lives and livelihoods, especially for those who relied significantly on their daily wages for sustenance. A survey conducted by GeoPoll in collaboration with the United States Agency for International Development (USAID) and Family Health International (FHI360) on the long-term impacts of the Ebola outbreak found that $45 \%$ of respondents in Sierra Leone and $32 \%$ of respondents in Liberia reported a drop in family income between June 2014 and June 2015. ${ }^{5}$ While nations in the global north are able to support their citizens with relief packages during the current COVID-19 pandemic, those in West Africa and other developing nations of the world are simply not afforded the same privilege. Therefore, it is important that these people be factored into any response strategy being developed by governments as well as multilateral organizations and aid agencies around the world to ameliorate the impacts the pandemic is having and would continue to have on the world's most vulnerable people.

\section{On Aid and Humanitarian Services}

With at least 32 African countries closing their land, air, and sea borders, ${ }^{7}$ and many more countries doing so around the world, to curb the spread of the COVID-19 pandemic, there are fears about the potential disruption this measure could have on the delivery of critical aid and humanitarian assistance to vulnerable regions in Sub-Saharan Africa. ${ }^{8}$ In a recent statement from GAVI, the Vaccine Alliance, about 13.5 million people in 13 of the world's least developed countries will not be protected against measles, polio, or human papillomavirus due to major disruptions in routine vaccination campaigns and supply delivery to these regions caused by COVID-19 containment measures. ${ }^{9}$ Furthermore, travel restrictions in Kenya have delayed the delivery of much needed pesticides to fight a destructive locust outbreak in East Africa, ${ }^{10}$ which has threatened to adversely affect food supply in the region if left unchecked. It is important that governments do not fall into the trap of seeing the COVID-19 pandemic as only a health emergency, and any response strategy must incorporate a robust plan to ensure free movement of aid and humanitarian services across vulnerable regions.

\section{On other health sectors}

On April 10, 2020, barely 48 hours before the World Health Organization (WHO) was to declare an end to the Ebola virus outbreak in the DRC, a new case was reported in the northeastern region of the country. ${ }^{11}$ This unfortunate news came 52 days after the last confirmed case and 40 days after the last patient had been declared free of Ebola. ${ }^{11}$ The success recorded by the DRC in combatting Ebola so far has been dwarfed by the fact that more than twice the number of people who died from the outbreak eventually died from a preventable outbreak of measles. ${ }^{12}$ The DRC story has shown the devastating effects a nation could suffer from being drawn into a multi-front health battle as a result of neglecting other health sectors during the outbreak. Thus, it is important that essential healthcare services such as vaccination schemes for measles, polio, and tuberculosis are maintained, especially in nations where these diseases remain endemic throughout the period of the crisis.

\section{On Women and Girls}

Women and young girls are often one of the hardest hit demographics during any emergency or outbreak situation. This is especially true for societies without a sufficient infrastructure to cater to the wellbeing and safety of this group, even in the absence of an infectious disease outbreak, such as those found in Sub-Saharan Africa and other lowand middle-income countries. During the Ebola outbreak, essential resources were diverted from crucial sexual and reproductive health services, cases of rape rose dramatically, and under severe financial strains, young girls were forced to engage in survival sex, while families resorted to offering up their female children in forced early marriages. ${ }^{13,}{ }^{14}$ It is important that as nations respond to the rapidly evolving COVID-19 pandemic, sufficient emphasis is placed on ensuring that sexual and reproductive health services are not sacrificed for outbreak response strategies.

\section{On Children}

Infectious diseases outbreaks disproportionately affect children more severely than other groups, either directly through infection or indirectly through the loss of family members and loved ones. The Ebola outbreak was a truly traumatizing time for children, with loved ones dying from the 
outbreak and weak social support systems for such children in affected countries; they had no food, shelter, clothing, or necessary care. ${ }^{15}$ It is important that childcare and protection services be instituted in countries affected by the COVID-19 pandemic in order to prevent the risk of harm to children. This can be achieved in partnership with community gatekeepers such as community leaders, religious organizations, health workers, aid agencies, and humanitarian groups.

\section{On Misinformation}

Critical to the success of every outbreak response strategy is proper information dissemination between the health agencies and the community; however, it is even more important to ensure that only correct information is being spread, as misinformation may lead to heightened anxiety, fear, and in extreme cases, loss of life if left unchecked. For example, during Nigeria's short but critical Ebola outbreak in 2014, misinformation on the efficacy of salt water and bath in preventing EVD led to the hospitalization and death of about five people during the outbreak. ${ }^{16}$ Furthermore, there was widely spread misinformation on how safe it was to accept survivors back into society, resulting in the stigmatization of survivors and the development of post-traumatic stress disorder. $^{15}$ By working with anthropologists and social scientists, governments can gain a proper understanding of the social mechanisms surrounding the response of community members to infectious diseases outbreak and thus become better able to disseminate messages that enhance positive behavioral change, dispel myths, and clear up misconceptions.

\section{On Community Engagement and Mobilization Strategies}

In both recent Ebola outbreaks of West Africa (2014 to 2016) and the DRC (2018-2020), instead of seeing community actors as potential partners in tackling the epidemic, response agencies related with them as part of the problem. ${ }^{17}$ Cultural practices such as communal eating and burial practices were indeed obstacles to prevention and control efforts. In order to tackle them appropriately, it was crucial that community gatekeepers be invited to the dialogue from the onset and be given a voice during negotiations and response planning activities. Any other approach would only act to breed distrust and fuel suspicions in the local populace as seen in the early stages of both outbreaks. In the DRC for example, where the Catholic Church is directly responsible for approximately $40 \%$ of the healthcare infrastructure, ${ }^{18}$ any outbreak response effort must, by necessity, involve religious organizations which are the major players at the forefront of the response. ${ }^{19}$ For a disease like COVID-19 with which many communities are unfamiliar, it is important that information on behavior modification, such as self-isolation and social distancing as well as cessation of cultural practices known to fuel transmission, come from trusted community sources, such as local leaders, community health workers, or religious bodies.

\section{Conclusion}

In conclusion, low- and lower-middle income countries in Africa and elsewhere may find it difficult to cope with the health and socio-economic effects of the pandemic alone.
Thus, there is a need for global solidarity and for the more privileged of us to be ready to offer assistance to those in need of support. It is clear that COVID-19 does not recognize geographical boundaries, and no nation will be safe until every nation is safe. It is also crucial that we are ready to look back on our previous experiences and struggles with disease outbreaks to pick out lessons, strengthen our weaknesses, and consolidate our strengths. Though social distancing may help us slow the spread of the deadly virus, it will not help us win the war against it. Our strongest hope remains in finding a vaccine against the virus; once we do, we ought to go on an offensive to eradicate it from every human population, like the Ebola rVSV-xebov vaccine which has been found to be $100 \%$ effective ${ }^{20}$ and critical in the fight against the resurgence of the deadly virus since $2017 .{ }^{21}$

\section{Conflict of Interest Disclosures}

The author declares no conflict of interest.

\section{Ethical Approval}

Not applicable.

\section{Funding/Support}

None.

\section{References}

1. Egypt Today. Egypt Announces First Coronavirus Infection. Egypt Today. February 14, 2020. https://www.egypttoday.com/ Article/1/81641/Egypt-announces-first-Coronavirus-infection.

2. Africa CDC. Coronavirus Disease 2019 (COVID-19). https:// africacdc.org/covid-19/. Published 2020.

3. Adepoju P. Nigeria responds to COVID-19; first case detected in sub-Saharan Africa. Nat Med. 2020;26(4):444-448. doi:10.1038/ d41591-020-00004-2.

4. Arias D. Keeping Africa's Food Supplies Strong During COVID-19: Lessons from Past Crises. World Bank website. https://blogs. worldbank.org/nasikiliza/keeping-africas-food-supplies-strongduring-covid-19-lessons-past-crises. Published 2020. Accessed May 16, 2020.

5. Sauvage-Mar M. How to Apply Lessons Learned from the Ebola Response to COVID-19. GeoPoll website. https://www.geopoll. com/blog/ebola-to-covid-19-coronavirus/. Published 2020. Accessed May 16, 2020.

6. Husain A, Sandström S, Greb F, Groder J, Pallanch C. COVID-19: Potential Impact on the World's Poorest People. https://docs.wfp. org/api/documents/WFP-0000114040/download/. Published 2020.

7. Anna C. At Least 32 African Nations Close Borders, Raising Fears about Critical Aid Deliveries. The Globe and Mail website. https:// www.theglobeandmail.com/world/article-at-least-32-africannations-close-borders-raising-fears-about/. Published 2020.

8. Magome M. As Africa Locks Down, Some Deliveries of Aid are Threatened. AP News. April 6, 2020. Available from: https:// apnews.com/8a097e1cd81ab2942477c98fcf55442d?fbcl id=IwAR1 hXX11SBBjDrwKkmLIoEWG-yx92TPOfSN_aK_ YUA40SIgJVP5VI2U80po.

9. Gavi, The Vaccine Alliance. COVID-19: Massive Impact on LowerIncome Countries Threatens more Disease Outbreaks. https:// www.gavi.org/news/media-room/covid-19-massive-impact-lowerincome-countries-threatens-more-disease-outbreaks.

10. Aljazeera. Alarm as Coronavirus Curbs Disrupt East Africa Fight on Locusts. Aljazeera. April 3, 2020. https://www.aljazeera.com/ news/2020/04/alarm-coronavirus-curbs-disrupt-east-africa-fight- 
locusts-200403173558211.html.

11. Médecins Sans Frontières. New Ebola Cases Confirmed in DRC Days before Expected end of Outbreak. Project Update; 2020. https://www.msf.org/new-ebola-cases-confirmed-drc.

12. DR Congo Measles: More Than 6,000 Dead in World's Worst Outbreak. BBC News. January 8, 2020. https://www.bbc.com/ news/world-africa-51028791.

13. Plan International. Teenage Pregnancy Rates Rise in Ebola-Stricken West Africa. Plan International website. https://plan-international. org/news/2014-11-17-teenage-pregnancy-rates-rise-ebolastricken-west-africa. Published 2014.

14. Werber C. How Ebola Led to More Teenage Pregnancy in West Africa. Quartz Africa. November 6, 2015. Available from: https://qz.com/africa/543354/how-ebola-led-to-more-teenagepregnancy-in-west-africa/

15. Chattoadhyay C. COVID-19: What Can We Learn from Previous Lessons in Responding to Disease Outbreaks in Low-Income Countries? ReliefWeb website. https://reliefweb.int/report/world/ covid-19-what-can-we-learn-previous-lessons-respondingdisease-outbreaks-low-income. Published 2020.

16. Oleribe OO, Crossey MM, Taylor-Robinson SD. Nigerian response to the 2014 Ebola viral disease outbreak: lessons and cautions. Pan Afr Med J. 2015;22(Suppl 1):13. doi:10.11694/pamj. supp.2015.22.1.6490.

17. O'Callaghan S. Covid-19: Five Lessons from Ebola. Overseas Development Institute website. https://www.odi.org/blogs/16779covid-19-five-lessons-ebola. Published 2020

18. Humanitarian Practice Network (HPN). Responding to Ebola in the Democratic Republic of Congo. United Kingdom: HPN; 2020.

19. Marshall K, Wilkinson O, Robinson D. Religion and COVID-19: Four Lessons from the Ebola Experience. Oxfam Blogs. https://cutt. ly/CsrM5qv. Published 2020

20. Henao-Restrepo AM, Camacho A, Longini IM, et al. Efficacy and effectiveness of an rVSV-vectored vaccine in preventing Ebola virus disease: final results from the Guinea ring vaccination, open-label, cluster-randomised trial (Ebola Ça Suffit!). Lancet. 2017;389(10068):505-518. doi:10.1016/s0140-6736(16)326216.

21. World Health Organization (WHO). Ebola then and Now: Eight Lessons from West Africa that Were Applied in the Democratic Republic of the Congo. https://www.who.int/news-room/featurestories/detail/ebola-then-and-now. Published 2020. 